\title{
Generating chemokine analogues with enhanced pharmacological properties using phage display
}

Karim Dorgham $^{1 *}$, Fabrice Cerini*, Hubert Gaertner ${ }^{2}$, Astrid Melotti ${ }^{2}$, Irène Rossitto-Borlat ${ }^{2}$, Guy Gorochov ${ }^{1,2 \#} \&$ Oliver Hartley ${ }^{3 \#}$

${ }^{1}$ Sorbonne Universités, UPMC Univ Paris 06, Inserm UMRS1135, Centre d'Immunologie et des Maladies Infectieuses (Cimi-Paris), 83 Bd de l'hôpital, F-75013, Paris, France.

Department of Pathology and Immunology, Faculty of Medicine, University of Geneva, 1 rue Michel Servet, 1211 Geneva 4, Switzerland.

${ }^{3}$ AP-HP, Groupement Hospitalier Pitié-Salpêtrière, Département d'Immunologie, 83 Bd de l'hôpital, F-75013, Paris, France

* These authors made an equal contribution to the manuscript

\#Co-corresponding authors: guy.gorochov@upmc.fr, oliver.hartley@unige.ch. 
Chemokine phage display

\section{Contents}

1. Introduction 3

2. Methods 6

$\begin{array}{ll}2.1 \text { Library design and construction } & 6\end{array}$

$\begin{array}{ll}2.2 \text { Selection of libraries on cells } & 13\end{array}$

3. Limitations 18

$\begin{array}{ll}\text { The atypical chemokine receptor DARC (ACKR1) } & 18\end{array}$

4. Perspectives 20

4.1 A chemokine-based HIV prevention strategy 20

4.2 New tools to study CCR5 pharmacology and cell biology 20

4.3 An intrakine to protect cells from HIV infection and a vaccine adjuvant 21

4.4 A prototypic inhibitor of CX3CR1, the Fractalkine/CX3CL1 receptor 21 


\section{Introduction}

\section{Chemokines in health and disease}

Chemokines (reviewed in (Griffith, Sokol, and Luster, 2014, Raman, Sobolik-Delmaire, and Richmond, 2011)) are a family of small (7-10 kDa) proteins that engage chemokine receptors, which are themselves members of the G protein-coupled receptor (GPCR) superfamily. There are approximately 50 human chemokines and 20 human chemokine receptors. The major role of the chemokine - chemokine receptor system is in immunity, where chemokine activity underlies processes ranging from coordinating the circulation of leukocytes around the lymphatic system to driving the egress of effector cells from the bloodstream into sites of inflammation (Griffith et al, 2014). Additional roles for chemokines include embryogenesis, wound healing and angiogenesis (Raman et al, 2011).

Chemokines are key players in inflammatory diseases such as rheumatoid arthritis, atherosclerosis and asthma (reviewed in (Koelink et al, 2012)) and in the evolution of and metastatic spread of tumors (reviewed in (Balkwill, 2012)). The strategy of adding chemokine receptor agonists to vaccine adjuvants in order to boost immune reactions is being explored (Bobanga, Petrosiute, and Huang, 2013), and the chemokine receptors that are used by HIV as entry coreceptors represent important targets for antiviral prevention and therapy (Kuhmann \& Hartley, 2008).

Hence the chemokine - chemokine receptor system presents a number of potential targets for combating pathology (Viola \& Luster, 2008), but in spite of significant investment in small molecule drug development programs since the 1990s, only two drugs that target chemokine receptors have been licensed so far: maraviroc, a CCR5 inhibitor used for HIV therapy (Kuritzkes, Kar, and Kirkpatrick, 2008), and plerixafor (Uy, Rettig, and Cashen, 2008), a CXCR4 inhibitor used to mobilize hematopoietic stem cells. In addition to representing valuable research tools for the study of chemokine receptor structure, pharmacology and cell biology, engineered chemokine analogs have the potential be developed into new medicines. In this chapter we describe the use of phage display to isolate chemokine analogs with promising pharmacological activity.

\section{Chemokine structure and activity}

Chemokines share a characteristic tertiary structure featuring a folded core region, stabilized by disulfide bridges, from which appends a flexible N-terminal domain (Fernandez \& Lolis, 2002) (Fig. 1). Numerous structure-activity studies have revealed a two-site mechanism for chemokine - chemokine receptor engagement (Fernandez \& Lolis, 2002, Wells et al, 1996, Allen, Crown, and Handel, 2007). Initially high affinity and high specificity engagement is achieved through an 'address' interaction between the folded core region of the chemokine 
and the extracellular region of the chemokine receptor (also referred to as chemokine recognition site 1, CRS1 (Scholten et al, 2012)). Subsequently, the flexible N-terminal domain of chemokine engages the transmembrane domain of the chemokine receptor (now referred to as CRS2 (Scholten et al, 2012)) providing a 'message' interaction that leads to signal transduction.

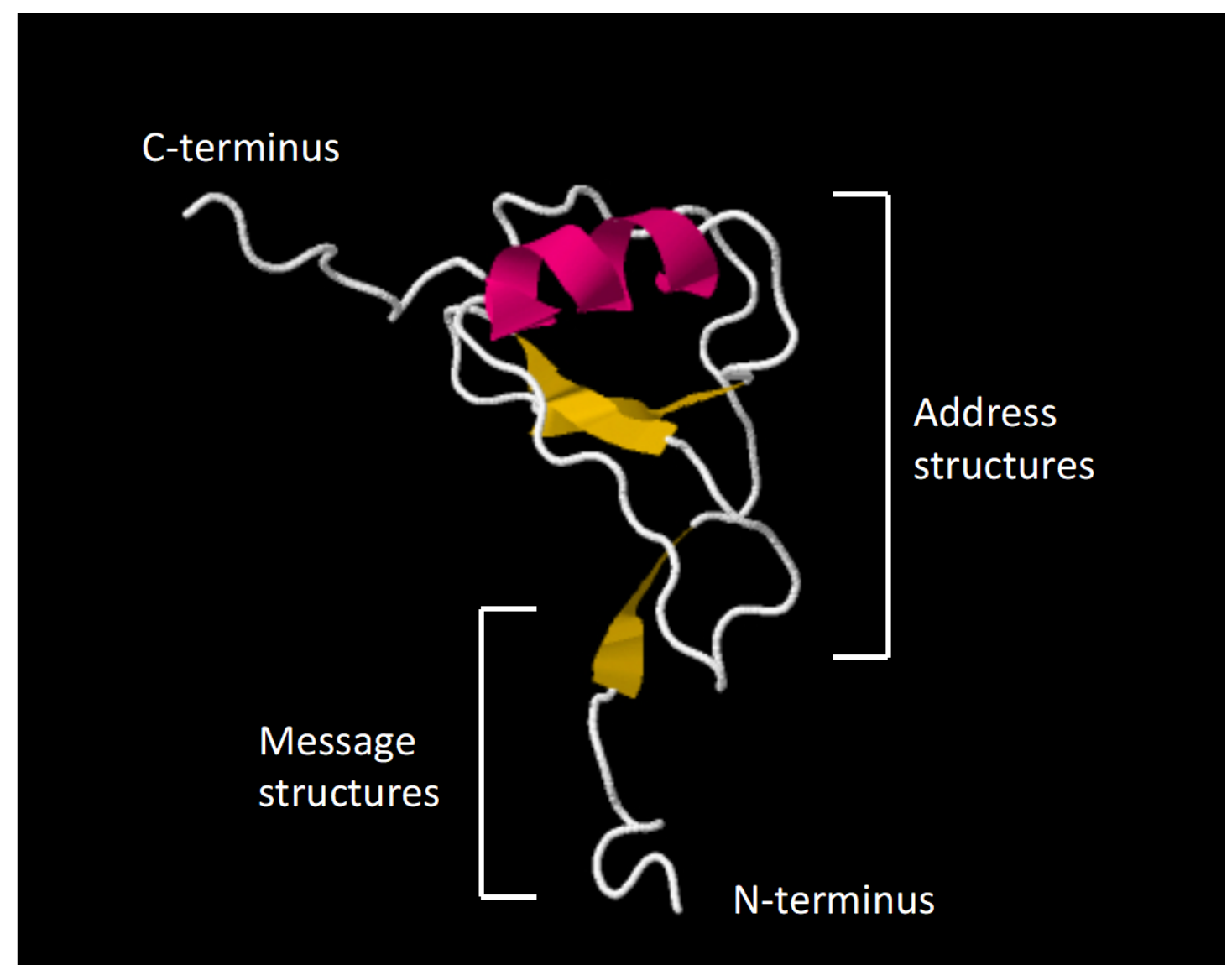

Figure 1. Chemokine structure and function. Chemokines share a common tertiary structure (here MCP-1/CCL2 is shown as an example - ribbon structure produced using jmol from PDB structure 1DOM). The rigid, folded core of the protein carries 'address' structures (CRS1) that provide high affinity and high specificity interactions with chemokine receptors, and the flexible N-terminal region carries 'message' structures (CRS2) that affect receptor function. The C-terminus does not participate in receptor interaction and can be modified without affecting pharmacology.

Numerous examples of chemokine analogs featuring modified $\mathrm{N}$-terminal regions exhibiting modified functional activity have been described, including antagonists, partial agonists and superagonists (Allen et al, 2007, Hartley \& Offord, 2005).

\section{Applying phage display technology to chemokine receptors}

Phage display technology (Sidhu, 2001) involves the insertion of libraries encoding ligands, most frequently antibodies or peptides, in frame with filamentous phage coat proteins so that the encoded gene is expressed on the phage surface. Coupling of genotype and phenotype in 
this way makes it possible to use in vitro evolution approaches to isolate extremely rare phage clones encoding ligands with desirable characteristics from vast libraries.

While phage display has been used quite extensively to isolate ligands to receptors for which the extracellular domains can be produced as isolated soluble proteins, its application to integral membrane proteins such as GPCRs is more challenging (Hartley, 2002). Firstly, expressing, purifying and presenting integral membrane proteins in their physiological conformations is an obstacle well known to the GPCR structural biology field, and an added challenge with conventional phage display is to efficiently attaching receptors to the solid phase without affecting their conformation. One solution is to bypass purification and present the receptor in the context of the cell in which it is expressed. Screening unbiased peptide or antibody libraries on intact cells carries a major risk of isolating ligands that bind to other irrelevant targets on the cell surface (Hartley, 2002), but is more straightforward when the phage libraries are based on the receptor's own ligands, because the libraries are naturally biased towards the target. Chemokine receptors, with their two-site mechanism of ligand interaction, are particularly attractive targets, because by targeting mutations to the flexible $\mathrm{N}$-terminal domain it is possible to selectively manipulate pharmacological activity (CRS2) without affecting receptor affinity and specificity (CRS1).

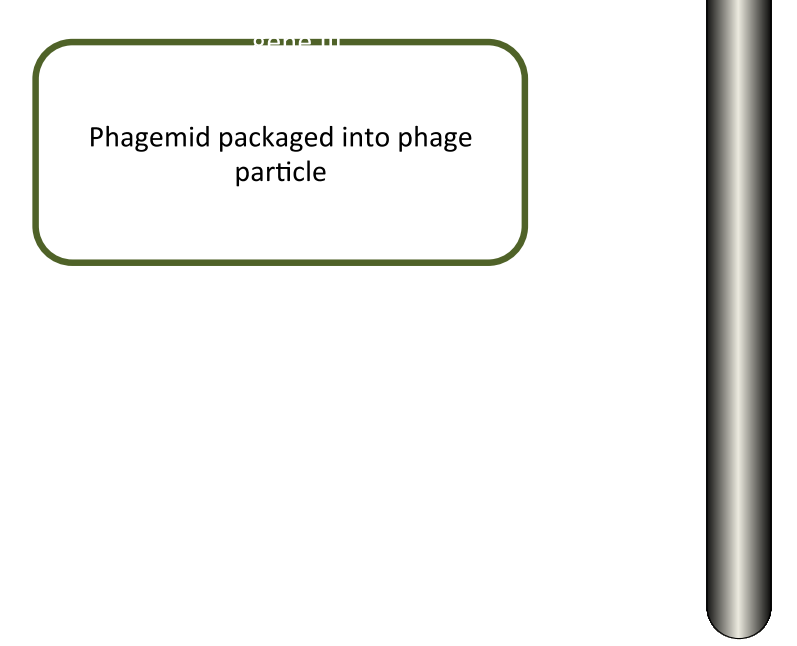

Figure 2. Chemokine phage display. Libraries encoding chemokine variants are cloned for expression as C-terminal fusions to the phage minor coat protein, $\mathrm{g} 3 \mathrm{p}$. 


\section{Methods}

Of the five components involved in a typical chemokine phage display selection program (Fig. 3), only the library design and construction and the panning on cells components will be detailed in this chapter. Methods for the production and purification of phage are common to the majority of phage display strategies and are well described elsewhere e.g. (Barbas, 2000, Kay, Winter, and McCafferty, 1996, Clackson \& Lowman, 2004). The production of chemokine analogues using both recombinant (Horuk, Reilly, and Yansura, 1997, Offord, Gaertner, Wells, and Proudfoot, 1997) and chemical synthesis (Dawson, 1997, Clark-Lewis, Vo, Owen, and Anderson, 1997) platforms has been similarly well documented. Finally, choice of the method or methods used for the pharmacological evaluation of chemokine variants depends on the target receptor and the pharmacological output of interest.

Library design

and construction

Figure 3. Components of a complete chemokine phage display program. Libraries are designed and constructed, and the encoded phage clones are produced and purified. Selection involves cycles of panning on cells followed by amplification of captured phage. After several such rounds, variants isolated from the library are produced and subjected to pharmacological evaluation. New structureactivity insights can be used to design next-generation libraries, ultimately leading to the identification of chemokine analogs with the desired pharmacological properties.

\subsection{Library design and construction}

Choice of phage display system

Since the C-terminus of chemokines can generally be modified without affecting pharmacological activity, we chose a phage display strategy in which chemokine variants are fused via their C-termini to the bacteriophage g3p minor coat protein. From the numerous phage display vectors have been designed for $\mathrm{g} 3 \mathrm{p}$ fusion expression we opted to use the wellcharacterized pHEN-1 phagemid (Hoogenboom et al, 1991), using NcoI and NotI as cloning sites (Fig. 4). 

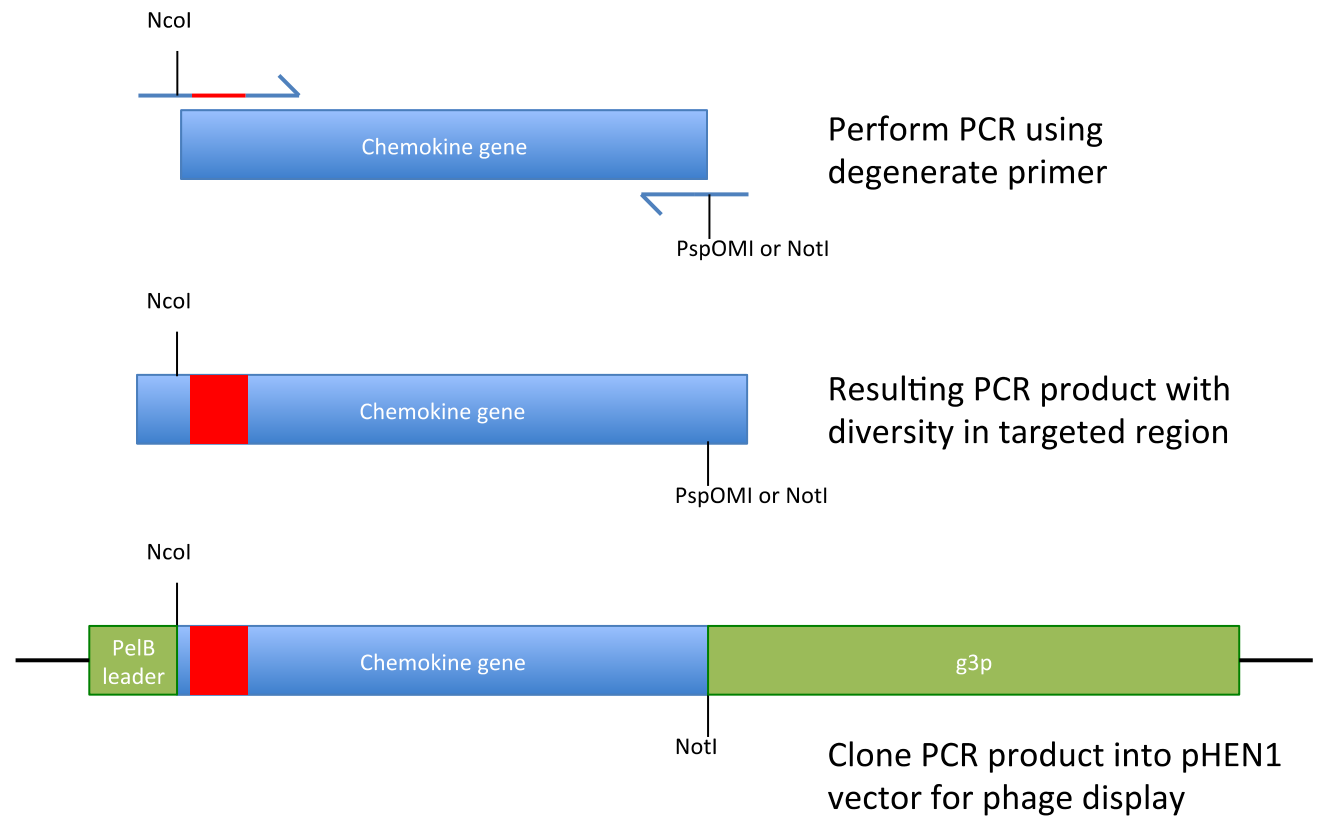

Figure 4. Cloning chemokine libraries for phage display. The chemokine gene (blue) is amplified by oligonucleotide primers that introduce diversity into the targeted region (red) and append appropriate restriction sites. The amplified fragment is digested and cloned upstream and in-frame with the phage minor coat protein g3p (green). For libraries based on RANTES/CCL5 the PCR fragment was digested using PspOMI as the 3' restriction enzyme. PspOMI and NotI generate compatible cohesive ends.

\section{Introducing library diversity}

Diversity can be readily introduced to a specific region of a gene by PCR amplification using degenerate oligonucleotide primers (some examples are shown in Table 1). Most commonly, complete randomization of a specific amino acid position is achieved by encoding the degenerate codon NNK (where $\mathrm{N}$ is $\mathrm{A}, \mathrm{C}, \mathrm{G}$ or $\mathrm{T}$ and $\mathrm{K}$ is $\mathrm{G}$ or $\mathrm{T}$ ), covering all twenty amino acids, plus one stop codon (the amber codon, TAG), which can be suppressed using an appropriate E. Coli host strain (generally the SupE-positive TG1 strain is used).

\begin{tabular}{|l|l|l|}
\hline Library & \multicolumn{1}{|c|}{ 5' $^{\prime}$ oligonucleotide primer } & Reference \\
\hline $\begin{array}{l}\text { RANTES/CCL5 } \\
\text { Library 2 }\end{array}$ & $\begin{array}{l}\text { 5' CAG CCG GCC ATG GCC NNK NNK CCA NNK } \\
\text { NNK NNK CAA NCC ACA CCC TGC TGC TTT GCC } \\
\text { TAC ATT GCC CGC 3' }\end{array}$ & $\begin{array}{l}\text { (Gaertner et } \\
\text { al, 2008) }\end{array}$ \\
\hline $\begin{array}{l}\text { RANTES/CCL5 } \\
\text { Library 5 }\end{array}$ & $\begin{array}{l}5^{\prime} \text { CAG CCG GCC ATG GCC CAG GGT CCA CCT } \\
\text { TTG ATG NNK NNK NNK NNK TGC TGC TTT GCC }\end{array}$ & $\begin{array}{l}\text { (Gaertner et } \\
\text { al, 2008) }\end{array}$ \\
\hline $\begin{array}{l}\text { Tractalkine/CX3L1 } \\
\text { Library 1 }\end{array}$ & $\begin{array}{l}5^{\prime} \text { CCG GCC ATG GCC NNK CAN NNK NNK GNC } \\
\text { NTG NCA AAA TGC AAC ATC ACG TGC 3' }\end{array}$ & $\begin{array}{l}\text { (Dorgham et } \\
\text { al, 2009) }\end{array}$ \\
\hline
\end{tabular}

Table 1. Examples of degenerate oligonucleotide primers used to generate chemokine phage display libraries. The primers shown range from 51 to 69 bases in length and encode theoretical diversities from $1.6 \times 10^{5}$ (RANTES/CCL5 Library 5) to $1.3 \times 10^{7}$ (RANTES/CCL5 Library 2)

In our experience the quality of the primers used for library amplification is key to success. In many cases the required upstream primers will be in excess of 60 bases in length, and we 
recommend that these should be ordered from providers offering premium quality synthesis and purification. Libraries generated using low quality primers will include a higher proportion of truncation and frame shift mutants, wasting valuable library space and potentially having an adverse effect on the outcome of selection experiments (see Section 2.2 below).

\section{How much diversity is feasible?}

Work with antibody phage display has shown that the larger the size of initial library that can feasibly be sampled, the higher the probability of isolating a high affinity ligand against a given target (Griffiths et al, 1994). While PCR fragments encoding very high diversity can be readily obtained and ligated into phage display vectors, the factor limiting final library size is the number of host $E$. coli cells that can be transformed with the ligated phage display vector, and if this figure is not in excess of the theoretical diversity (i.e. the total number of encoded amino acid combinations), only a fraction of the diversity will be sampled, and potentially active sequences will not be isolated. Large-scale transformation of $E$. coli to generate large libraries is an onerous task. For laboratories not specialized in phage display we would recommend a maximum library size of $3.2 \times 10^{6}$ (i.e. five positions fully randomized, $20^{5}$ ).

\section{Partial diversity}

A greater number of residues can be mutagenized without generating unfeasibly high theoretical diversity when partial randomization approaches are used. In partial randomization, codon sets more restrictive than NNK, encoding fewer amino acids, are used (e.g NCA, covering ACA, CCA, GCA and TCA - Thr, Pro, Ala and Ser). The choice of the restricted codon set can be driven by the size, charge, polarity or hydrophobicity of the encoded amino acids, according to sequence alignments of related chemokines, and/or structure-activity clues emerging from selection of a previous library. Several examples of libraries encoding partial diversity at certain positions are shown in Table 2.

\section{Chemokine walking - exploring diversity step-by-step}

'Chemokine walking' is strategy that we have used to fully explore diversity over a relatively long stretch of amino acids without the need to generate very large libraries. A relatively small initial library is created, and selection of this library provides structure-activity insights that can be used to inform the design of a next-generation library, in which amino acids identified as important for activity are fixed, and diversity is introduced to neighboring positions. Moving from the modest anti-HIV chemokine analogs isolated from a first

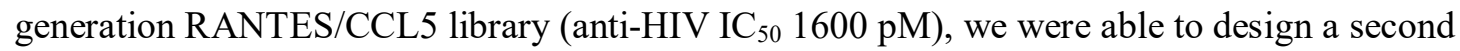
generation library (Library 2 in Table 2 ) that provided analogs with further improved anti- 
Chemokine phage display

HIV activity (650 pM) (Gaertner et al, 2008). Third generation libraries developed according to these improved sequences (Libraries 5 and 6 in Table 2) ultimately yielded fully optimized anti-HIV chemokines $(<30 \mathrm{pM})$ (Gaertner et al, 2008). It is noteworthy that these molecules were obtained by exploring a region ten amino acids in length; it would not have been technically feasible to generate and select a single library of diversity $20^{10}$.

A complete summary of the phage chemokine libraries that we have produced and selected, including unpublished work, is shown in Table 2. 
Chemokine phage display

\begin{tabular}{|c|c|c|c|c|c|}
\hline $\begin{array}{l}\text { Chemokine } \\
\text { Library }\end{array}$ & $\mathrm{N}$-terminal sequence & $\begin{array}{l}\text { Theoretical } \\
\text { diversity }\end{array}$ & $\begin{array}{l}\text { Library } \\
\text { size } \\
\text { obtained }\end{array}$ & $\begin{array}{l}\text { Examples of selected } \\
\text { sequences }\end{array}$ & References \\
\hline RANTES/Ca.5 & \multicolumn{5}{|l|}{ SPYSSDTTPCC } \\
\hline Library 1 & XS\#XSSX\#和 & $2.0 \times 10^{6}$ & $5 \times 10^{6}$ & $\begin{array}{l}\text { LSPVSSQSSACC } \\
\text { TPI-RANTES }) \\
\text { FSPLSSQSSACC } \\
\text { TP2-RANTES }) \\
\text { MSPLSSQASACC } \\
\text { (P) } \overline{7-R A N T E S ~})\end{array}$ & $\begin{array}{l}\text { (Hartley et al, } \\
\text { 2003); } \\
\text { (Dorgham et al, } \\
2008 \text { ) }\end{array}$ \\
\hline Library 2 & 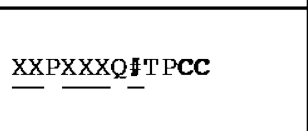 & $1.28 \times 10^{7}$ & $3.1 \times 10^{7}$ & 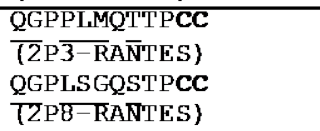 & $\begin{array}{l}\text { (Gaertner et al, } \\
\text { 2008) }\end{array}$ \\
\hline Library 3 & LSPVSSQSSACCXXXXX & $3.2 \times 10^{6}$ & $3.1 \times 10^{7}$ & $\begin{array}{l}\text { LSPVSSQSSACCFAYIA } \\
\text { (P1-RANTES) }\end{array}$ & $\begin{array}{l}\text { OH etal, } \\
\text { unpublished }\end{array}$ \\
\hline Library 4 & $\begin{array}{l}\text { LSPVSSQSSACC...XX } \\
\text { XSXXC }\end{array}$ & $3.2 \times 10^{6}$ & $2.2 \times 10^{7}$ & $\begin{array}{l}\text { LSPVSSQSSACC . . FYT } \\
\text { SGKC } \\
\text { (PI-RANTES) }\end{array}$ & $\begin{array}{l}\text { OH etal, } \\
\text { unpublished }\end{array}$ \\
\hline Library 5 & QGPPLMXXXXсcC & $1.6 \times 10^{5}$ & $1 \times 10^{6}$ & $\begin{array}{l}\text { QGPPLMATQSCC } \\
\text { (5P12-RANTES) } \\
\text { QGPPLMSLQVCC } \\
\text { (5P14-RANTES) }\end{array}$ & $\begin{array}{l}\text { (Gaertner et al, } \\
\text { 2008) }\end{array}$ \\
\hline Library 6 & QGP $\pm 0 \times X X X \times C C$ & $3.8 \times 10^{7}$ & $5.5 \times 10^{7}$ & $\begin{array}{l}\text { QGPPGDIVLACC } \\
\text { (6P4-RANTES) }\end{array}$ & $\begin{array}{l}\text { (Gaertner et al, } \\
2008 \text { ) }\end{array}$ \\
\hline Library 7 & QGPPXXWXQXCC & $1.6 \times 10^{5}$ & $1.2 \times 10^{7}$ & 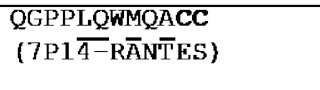 & $\begin{array}{l}\text { (Gaertner et al, } \\
\text { 2008) }\end{array}$ \\
\hline Library 8 & QGPLXXXXQVCC & $1.6 \times 10^{5}$ & $1.0 \times 10^{6}$ & $\begin{array}{l}\text { QGPLSGWAQVCC } \\
\text { (8P6-RANTES) }\end{array}$ & $\begin{array}{l}\text { (Gaertner et al, } \\
\text { 2008) }\end{array}$ \\
\hline Library 9 & XXXXXSDTTPCC & $3.2 \times 10^{6}$ & $3.1 \times 10^{7}$ & $\begin{array}{l}\text { QWVMGSDTTPCC } \\
\text { (9P10-RANTES) } \\
\text { QGQRI SDTT-CC } \\
\text { (9PI-RANTES) }\end{array}$ & $\begin{array}{l}\text { OH et al, } \\
\text { unpublished }\end{array}$ \\
\hline IL-8/CXCL8 & \multicolumn{5}{|l|}{ SAKELRCQC } \\
\hline Library 1 & XXXXXLRCQC & $3.2 \times 10^{6}$ & $9.0 \times 10^{6}$ & Selection failed & $\begin{array}{l}\mathrm{OH} \text { et al, } \\
\text { unpublished }\end{array}$ \\
\hline $\begin{array}{l}\text { Fractal- } \\
\text { kine/CX3CI.1 }\end{array}$ & \multicolumn{5}{|l|}{ - QHHGVTKCNITC } \\
\hline Library 1 & X\&XX\$S\#KCNITC & $1.5 \times 10^{6}$ & $5 \times 10^{6}$ & $\begin{array}{l}\text { ILDNGVSKCNITC } \\
\text { (F1-CX3CL1) }\end{array}$ & $\begin{array}{l}\text { (Dorgham et al, } \\
\text { 2009) }\end{array}$ \\
\hline Library 2 & -XXX\$S\#KCNITC & $4 \times 10^{5}$ & $2 \times 10^{6}$ & $\begin{array}{l}\text {-QPGGVSKCNITC } \\
\text { (F3-CX3CL1) }\end{array}$ & KD, unpublished \\
\hline Mip3a/CCI.20 & \multicolumn{5}{|l|}{-ASNFDCC } \\
\hline Library 1 & $x x !+>+c c$ & $1.1 \times 10^{6}$ & $1 \times 10^{6}$ & $\begin{array}{l}\text { GRMQQECC } \\
\text { TM1-CCL20) } \\
\text { QGTYLQCC } \\
\text { (M2-CCL20) }\end{array}$ & KD, unpublished \\
\hline Library 2 & $-x+£ x \operatorname{cc} x$ & $6.6 \times 10^{5}$ & $1 \times 10^{6}$ & $\begin{array}{l}\text {-VAQVQCCE } \\
\text { (M3-CCL2D) }\end{array}$ & KD, unpublished \\
\hline MCP-1/CCI.2 & \multicolumn{5}{|l|}{-QPDAINAPVTCC } \\
\hline Library 1 & XXXXAINAPVTCC & $1.6 \times 10^{5}$ & $1 \times 10^{6}$ & Selection failed & KD, unpublished \\
\hline Library 2 & -XXXXINAPVTCC & $1.6 \times 10^{5}$ & $1 \times 10^{6}$ & Confidential & $\begin{array}{l}\text { KD et al, in } \\
\text { preparation }\end{array}$ \\
\hline IP10/CXC1.10 & \multicolumn{5}{|l|}{-VPLSRTVRCTC } \\
\hline Library 1 & XXXXSRTVRCTC & $1.6 \times 10^{5}$ & $1 \times 10^{6}$ & Selection failed & KD, unpublished \\
\hline Library 2 & .XXXXRT'VRCTC & $1.6 \times 10^{5}$ & $1 \times 10^{6}$ & Selection failed & KD, unpublished \\
\hline SDF-1/CXO12 & \multicolumn{5}{|l|}{-KPVSLSYRCPC } \\
\hline Library 1 & XXPXXXSYRCPC & $3.2 \times 10^{6}$ & $1 \times 10^{6}$ & Selection failed & KD, unpublished \\
\hline
\end{tabular}

Table 2. Phage chemokine libraries constructed and selected by the authors to date. The following single character codes are used to describe possible amino acid combinations at given positions: $\mathrm{X}$ (any amino acid), \# (S, P, T or A), $\ddagger(\mathrm{G}, \mathrm{L}$ or P), ० (G, L or M), \& (L, P, Q or R), \$ (V, A, D or G), § (L, M or V), + (N, Y, Q, H, K, D or E), £ (F, M, L, I or V), ! (S, I, M, T, N, K or R) and > (F, S, Q, W, L, Y or C). 


\subsubsection{Required Materials}

- pHEN-1 phagemid vector for digestion

- Restriction enzymes NcoI, PspOMI, NotI (NEB R0193S, R0653S, R0189S)

- 10x digestion buffers (NEBuffer 3.1 and NEBuffer 4, NEB B7004S and B7203S, )

- Calf intestinal alkaline phosphatase (NEB M0290S)

- Forward and reverse primers for PCR

- $\quad$ Taq polymerase (Thermo Fisher 18038-042)

- DNA purification minicolumn kit (Promega A9282)

- $\quad$ T4 DNA ligase (NEB M0202S)

- Electrocompetent E. coli TG1 cells (Agilent 200123)

- Gene Pulser®/MicroPulser ${ }^{\mathrm{TM}}$ Electroporation Cuvettes, $0.1 \mathrm{~cm}$ gap (Bio-Rad 1652083)

- $\quad$ MicroPulser ${ }^{\mathrm{TM}}$ Electroporator (Bio-Rad 1652100)

\subsubsection{Library construction}

1. Perform NcoI / NotI digestion of $15 \mu \mathrm{g}$ of pHEN-1 plasmid DNA.

- 10x digestion buffer NEBuffer 3.1 $10 \mu \mathrm{L}$

- $\mathrm{pHEN-1} 15 \mu \mathrm{g}$

- $\quad$ NcoI (NEB R0193S) $3 \mu \mathrm{L}$

- $\quad \operatorname{NotI}(\mathrm{NEB}$ R0189S) $3 \mu \mathrm{L}$

- $\mathrm{ddH}_{2} \mathrm{O}$ to $100 \mu \mathrm{L}$

Incubate $2 \mathrm{~h}$ at $37^{\circ} \mathrm{C}$

2. Add $2.5 \mu \mathrm{L}$ units of calf intestine alkaline phosphatase to the digestion reaction, and incubate for a further $30 \mathrm{~min}$ at $37^{\circ} \mathrm{C}$

3. Gel purify the digested plasmid backbone using preparative scale $0.8 \%$ agarose gel. Excise the band corresponding to the digested plasmid backbone and cut the gel slice into 8 pieces of approximately equal size. Extract DNA from the gel using the DNA purification minicolumn kit using 1 column per gel slice. Elute each column with 50 $\mu \mathrm{L}$ water and pool the eluates. Verify the quality of the purification on an analytical gel $(0.8 \%$ agarose) .

4. PCR amplification using degenerate oligonucleotides. We empirically optimize PCR conditions (amount of template DNA and annealing temperature) prior to scale-up. As an example, the optimized reaction conditions used to generate the PCR fragment for Library 5 (ref). Depending on target library size, between five and twenty $50 \mu \mathrm{L}$ reactions are performed in parallel and then pooled. 
- 10x PCR buffer

- Template DNA

- $\mathrm{MgCl}_{2}(50 \mathrm{mM})$

- $\quad \mathrm{dNTP}(10 \mathrm{mM})$

- Primer forward $(25 \mu \mathrm{M})$

- Primer reverse $(25 \mu \mathrm{M})$

- Taq polymerase

- $\mathrm{ddH}_{2} \mathrm{O}$
$5 \mu \mathrm{L}$

$60 \mathrm{ng}$

$1.5 \mu \mathrm{L}$

$1 \mu \mathrm{L}$

$3 \mu \mathrm{L}$

$3 \mu \mathrm{L}$

$0.25 \mu \mathrm{L}$

to $50 \mu \mathrm{L}$

Thermocycling conditions: $94^{\circ} \mathrm{C} 5 \mathrm{~min}$, then 30 cycles $\left(94^{\circ} \mathrm{C} 1 \mathrm{~min}, 62^{\circ} \mathrm{C} 1 \mathrm{~min}\right.$, $\left.72^{\circ} \mathrm{C} 1 \mathrm{~min}\right)$.

5. Purify each PCR product using a DNA purification minicolumn kit, loading five 50 $\mu \mathrm{L}$ reactions per column, eluting each column with $50 \mu \mathrm{L}$ water. Pool eluted material.

6. Perform NcoI / PsPOMI digestion of the purified PCR fragment.

- 10x digestion buffer (NEBuffer 4)

$30 \mu \mathrm{L}$

- $\quad$ purified PCR product from step 5

$100 \mu \mathrm{L}$

- NcoI $20 \mu \mathrm{L}$

- PspOMI $20 \mu \mathrm{L}$

- $\mathrm{ddH}_{2} \mathrm{O}$ $130 \mu \mathrm{L}$

Incubate $3 \mathrm{~h}$ at $37^{\circ} \mathrm{C}$

7. Gel purify the digested PCR product using a $1.5 \%$ agarose gel. Excise the band corresponding to the digested PCR product and cut the gel slice into 6 pieces of approximately equal size. Extract DNA from the gel with the DNA purification minicolumn kit, using 1 column per gel slice. Verify the quality of the purification on an analytical gel (1.5\% agarose).

8. Perform test ligations using $2 \mu \mathrm{L}$ of digested backbone and varying volumes of digested PCR product. Below is an example of the test ligations performed for the preparation of Library 5

- 10x ligation buffer

$2 \mu \mathrm{L}$

- digested vector backbone

$2 \mu \mathrm{L}$

- digested PCR product

1,2 or $5 \mu \mathrm{L}$

- T4 DNA ligase

$1 \mu \mathrm{L}$

- $\mathrm{dd}_{2} \mathrm{O}$ to $10 \mu \mathrm{L}$

Incubate overnight at $15^{\circ} \mathrm{C}$

Evaluate the test ligations by electroporating them into electrocompetent $E$. coli TG1 and monitoring the number of transformants obtained. Define the optimal vector : insert ratio. 
9. Perform a 10-fold scaled up ligation reaction using the optimized vector : insert ratio. Use a DNA purification minicolumn kit to remove salts from the ligation reaction. Elute with $40 \mu \mathrm{L}$ water.

10. Electroporate the purified ligation mixture into electrocompetent E. coli TG1 using 2 $\mu \mathrm{L}$ ligation mixture per electroporation (i.e. 20 electroporations in total).

11. Pick up to 40 colonies from the titration plates for insert sequencing.

12. Harvest the colonies growing on the bioassay dishes by adding $10 \mathrm{~mL}$ of prewarmed 2YT ampicillin glucose and scraping. Pool the bacterial cell suspensions.

13. Remove a $100 \mu \mathrm{L}$ aliquot of the pooled bacterial cell suspension to produce an initial phage stock. Centrifuge the remainder at $3345 \mathrm{~g}$, resuspend in $50 \mathrm{~mL}$ of freeze medium and store $1 \mathrm{~mL}$ aliquots at $-80^{\circ} \mathrm{C}$.

For library quality control, 20 colonies are picked at random and PCR-screened with flanking primers LMB3 (5'CAG GAA ACA GCT ATG AC 3') and pHENseq (5' CTA TGC GGC CCC ATT CA 3' to ensure inserts of the expected size are present. Additionally, 10-20 colonies are picked at random and sequenced (using pHENseq as a sequencing primer) to verify library diversity and the levels of frameshift mutations.

\subsection{Selection of libraries on cells}

\section{Considerations}

In phage display experiments, the outcome of selection is the net result of two distinct selection pressure components (Fig. 5). The first is the user-defined selection component, which in chemokine phage display is based on the capacity of phage clones to interact with chemokine receptors expressed on living cells. The second is a consequence of the amplification process that is required between rounds of selection. Any phage clones with a growth advantage will be enriched during this phase. 


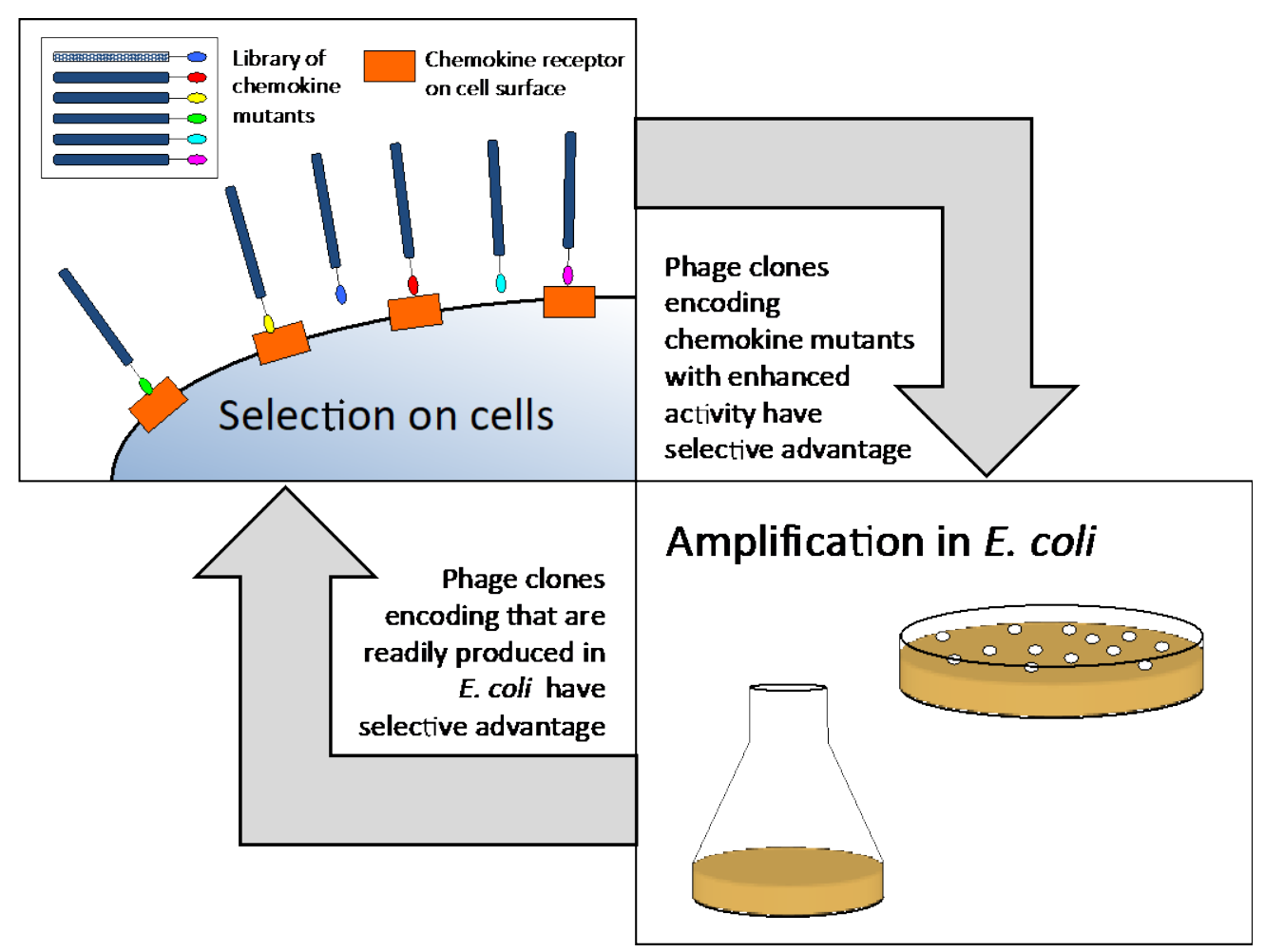

Figure 5. Two key parameters that affect the outcome of phage chemokine selection experiments. The outcome of selection depends on both the stringency of the user-defined panning step and the influence of growth advantage during the amplification step.

In order for useful phage clones to be selected, the user-defined selection component must be able to outrun the growth advantage component. Two criteria are essential for success. Firstly, the initial library should be of sufficiently high quality, with as low a proportion as possible of deletion and frame shift mutants, both of which will have an inherent growth advantage compared to clones expressing full-length fusion proteins. This criterion is addressed during initial library production (see Section 2.1 above). Secondly, the user-defined selection step must be sufficiently stringent to eliminate a large proportion of insufficiently active phage clones at each round of selection. Below we present as examples two chemokine phage display approaches that have worked well in our hands, one based on the selection of phage clones capable of inducing chemokine receptor internalization, the other based on selection of phage that remain attached to the cell surface in the presence of an excess of soluble chemokine competitor (Fig. 6). 


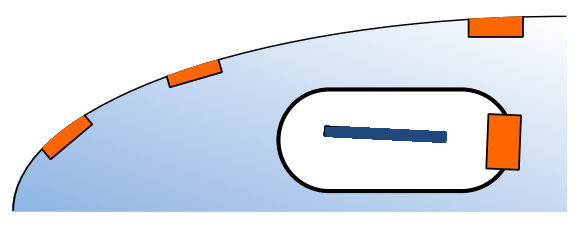

competitor

Figure 6. Two cell-based panning approaches for phage chemokine selection. In both cases the phage chemokine library is first incubated with live adherent cells. Subsequently, either internalizing phage are selected by using harsh washing conditions to strip surface associated phage from the cell surface and then recovering cell-associated phage (Option 1, upper panel), or high-affinity cell-surface binding phage are selected by extensively washing the cell surface and then eluting by adding an excess of native chemokine as a soluble competitor (Option 2, lower panel).

\subsubsection{Cell lines}

Cell lines expressing target chemokine receptors are obtained by stable transfection (ref) or lentiviral vector transduction of commonly available adherent cell lines (e.g. CHO, HEK-293, NIH-3T3, etc). The resulting cell populations are purified to clonality, with selected clones chosen according to evaluation of surface expression by flow cytometry. Additional characterization by immunofluorescence microscopy can be used to identify clones showing low levels of chemokine receptors in intracellular structures prior to ligand addition.

\subsubsection{Required materials}

- Cell lines (see 2.2.1 above)

- Phage library stock (approximately $10^{14} \mathrm{cfu} / \mathrm{mL}$ ) amplified, rescued and purified from initial E. coli library (see Section 2.1)

- Culture medium for cell lines (RPMI or DMEM as appropriate, Gibco GlutaMAX ${ }^{\mathrm{TM}}$ ) supplemented with penicillin-streptomycin (Gibco 15140-122) and 10\% fetal bovine serum (Sigma-Aldrich F0926)

- Phosphate buffered saline (PBS) (ThermoFisher 10010-023) 
- PBS supplemented with 1\% bovine serum albumin (Sigma-Aldrich A3912) (PBSBSA)

- $\quad 30 \mathrm{mM}$ Tris-HCl buffer, pH 8.0 supplemented with 1 mM EDTA (cell lysis buffer)

- 245 x $245 \mathrm{~mm}$ bioassay dishes (Thermofisher 240835)

- 2xTY liquid medium obtained by dissolving 12.4 g 2xTY powder (Sigma-Aldrich Y2627) in $400 \mathrm{~mL}$ milliQ water and autoclaving

- 2xTY agar prepared by dissolving $12.4 \mathrm{~g} 2 \mathrm{xTY}$ powder and $6.9 \mathrm{~g}$ bacto agar powder (BD 214010) in $400 \mathrm{~mL}$ milliQ water and autoclaving

- Ampicillin (Sigma-Aldrich A9393)

\section{Option 1:}

- Corning 6-well cell culture plate (Sigma-Aldrich CLS3516)

- Sterile disposable cell scraper (Sigma-Aldrich CLS3010-100EA)

Option 2:

- Corning $25 \mathrm{~cm}^{2}$ cell culture flasks (Sigma-Aldrich CLS3289)

- $2 \mathrm{M} \mathrm{NaCl}$ (high salt wash solution)

- $10 \mathrm{mM}$ glycine-NaOH buffer pH 11.4 (basic wash solution)

- $\quad$ PBS supplemented with $1 \mathrm{mM}$ EDTA (PBS-EDTA)

\subsubsection{Option 1: Selection for internalizing ligands}

1. (Day 1) Plate $10^{6}$ cells per well in a $25 \mathrm{~cm}^{2}$ culture flask in $5 \mathrm{~mL}$ culture medium. Grow cells overnight at $37^{\circ} \mathrm{C}, 5 \% \mathrm{CO}_{2}$.

2. (Day 2) Dilute phage stock in PBS to generate $100 \mu \mathrm{L}$ suspension at either $10^{10}$ $\mathrm{cfu} / \mathrm{mL}$ (low complexity libraries e.g. Library 5) or $10^{11} \mathrm{cfu} / \mathrm{mL}$ phage (higher complexity libraries e.g. Library 2). Pre-incubate with $100 \mu \mathrm{L}$ culture medium for $1 \mathrm{~h}$ at $37^{\circ} \mathrm{C}$.

3. Add the phage suspension to the medium covering the cells. Incubate 1 hour at $37^{\circ} \mathrm{C}$, $5 \% \mathrm{CO}_{2}$.

4. Wash cells five times at room temperature with $10 \mathrm{~mL}$ PBS-BSA.

5. Add $5 \mathrm{~mL}$ culture medium and incubate cells for a further $30 \mathrm{~min}$ at $37^{\circ} \mathrm{C}, 5 \% \mathrm{CO}_{2}$.

6. Wash cells three times with high salt wash solution, once with basic wash solution and once with PBS.

7. Detach cells with $5 \mathrm{~mL}$ PBS-EDTA and centrifuge for $5 \mathrm{~min}$ at $500 \mathrm{~g}$.

8. Resuspend the cell pellet in $500 \mu \mathrm{L}$ of cell lysis buffer.

9. Perform three freeze-thaw cycles by rapidly freezing the cell suspension in liquid $\mathrm{N}_{2}$ and then thawing at ambient temperature, vortex the suspension thoroughly between cycles. 
10. Centrifuge the suspensions for $5 \mathrm{~min}$ at $500 \mathrm{~g}$ and transfer the supernatant to a $15 \mathrm{~mL}$ Falcon tube.

11. Add $3 \mathrm{~mL} \log$ phase $E$. coli $\mathrm{TG} 1$ to the Falcon tube, incubate for $45 \mathrm{~min}$ at $37^{\circ} \mathrm{C}$ with gentle agitation.

12. Remove a $100 \mu \mathrm{L}$ aliquot for colony titration and spread the remaining bacterial culture on to a $245 \times 245 \mathrm{~mm}$ bioassay dish containing $2 \times \mathrm{XT}$ agar supplemented with ampicillin $(50 \mu \mathrm{g} / \mathrm{mL})$ and $1 \%$ glucose. Incubate overnight at $37^{\circ} \mathrm{C}$.

13. (Day 3) Pick up to 40 colonies from the titration plates for insert sequencing. Recover the colonies growing on the bioassay dish by adding $10 \mathrm{~mL}$ of prewarmed $2 \times T Y$ liquid medium supplemented with ampicillin $(50 \mu \mathrm{g} / \mathrm{mL})$ and $1 \%$ glucose to the surface and scraping.

14. Remove $100 \mu \mathrm{L}$ of the scraped bacterial cell suspension to produce phage stocks for the following selection round. Centrifuge the remainder at $3345 \mathrm{~g}$, resuspend in $5 \mathrm{~mL}$ of freeze medium and store at $-80^{\circ} \mathrm{C}$.

\subsubsection{Option 2: Selection for high affinity cell surface binding}

1. (Day 1) Plate $10^{6}$ transfected cells per well of a 6 -well cell culture plate in $4 \mathrm{~mL}$ cell culture medium. Grow cells overnight at $37^{\circ} \mathrm{C}, 5 \% \mathrm{CO}_{2}$.

2. (Day 2) Remove medium in the culture well and add $2 \mathrm{~mL}$ of fresh cell culture medium. Transfer an aliquot of phage library stock to provide a phage concentration of $10^{10} \mathrm{cfu} / \mathrm{mL}$ and incubate 1 hour at $37^{\circ} \mathrm{C}, 5 \% \mathrm{CO}_{2}$.

3. Wash cells ten times at room temperature with $10 \mathrm{~mL}$ of PBS and then scrape cells from the plate into $10 \mathrm{~mL}$ PBS-BSA.

4. Centrifuge the scraped cell suspension $\left(450 \mathrm{~g}, 5 \mathrm{~min}\right.$ at $\left.4^{\circ} \mathrm{C}\right)$ and resuspend the pellet $100 \mu \mathrm{L}$ PBS-BSA supplemented with $10 \mu \mathrm{M}$ native chemokine. Incubate for $20 \mathrm{~min}$ on ice.

5. Centrifuge the cell suspension $\left(450 \mathrm{~g}, 5 \mathrm{~min}\right.$ at $\left.4^{\circ} \mathrm{C}\right)$ and add $3 \mathrm{~mL}$ of a log-phase $E$. coli TG1 culture. Incubate for $45 \mathrm{~min}$ at $37^{\circ} \mathrm{C}$ with gentle agitation. For subsequent steps see steps 12, 13 and 14 from Section 2.2.3, above. 


\section{Limitations}

Using the methods described in this chapter we have isolated a range of valuable new chemokine analogs acting on CCR5 (Gaertner et al, 2008, Hartley et al, 2003, Dorgham et al, 2008), CX3CR1 (Dorgham et al, 2009, Poupel et al, 2013) (Summarized in Table 3). Recently, Hanes et al. used similar methods to isolate promising SDF-1/CXCL12 analogs that act as modulators of CXCR4 and ACKR3 (Hanes et al, 2015). However we have encountered problems isolating analogs against several other target chemokine receptors including ACKR1, CCR6, CXCR3 and CXCR4. Below we discuss the case of ACKR1, using it as an example to discuss potential explanations for selection failure in chemokine phage display.

\begin{tabular}{|c|c|c|c|c|}
\hline Receptor & Ligand & $\begin{array}{l}\text { N-terminal } \\
\text { sequence }\end{array}$ & Properties & References \\
\hline \multirow{8}{*}{ CCR5 } & RANTES/CCL5 & SPYSSDTTPCC & \multicolumn{2}{|l|}{ Natural ligand } \\
\hline & P1-RANTES & LSPVSSQSSACC & $\begin{array}{l}\text { anti-HIV, } \\
\text { antagonist }\end{array}$ & (Hartley et al, 2003) \\
\hline & P2-RANTES & FSPLSSQSSACC & $\begin{array}{l}\text { anti-HIV, } \\
\text { superagonist }\end{array}$ & (Hartley et al, 2003) \\
\hline & P7-RANTES & MSPLSSQASACC & $\begin{array}{l}\text { anti-HIV, } \\
\text { superagonist, } \\
\text { vaccine adjuvant }\end{array}$ & (Dorgham et al, 2008) \\
\hline & 5P12-RANTES & QGPPLMATQSCC & $\begin{array}{l}\text { anti-HIV, } \\
\text { antagonist }\end{array}$ & (Gaertner et al, 2008) \\
\hline & 5P14-RANTES & QGPPLMS LQVCC & $\begin{array}{l}\text { anti-HIV, biased } \\
\text { ligand? Modified } \\
\text { intracellular } \\
\text { trafficking }\end{array}$ & $\begin{array}{l}\text { (Gaertner et al, 2008), } \\
\text { (Zidar, 2011), } \\
\text { (Bonsch, Munteanu, } \\
\text { Rossitto-Borlat, } \\
\text { Furstenberg, and } \\
\text { Hartley, 2015) }\end{array}$ \\
\hline & 6P4-RANTES & QGPPGDIVLACC & $\begin{array}{l}\text { anti-HIV, } \\
\text { superagonist }\end{array}$ & (Gaertner et al, 2008) \\
\hline & 9P10-RANTES & QWVMGSDTTPCC & $\begin{array}{l}\text { anti-HIV, } \\
\text { superagonist }\end{array}$ & $\mathrm{OH}$ et al., unpublished \\
\hline \multirow{3}{*}{ CCR1 } & RANTES/CCL5 & SPYSSDTTPCC & \multicolumn{2}{|l|}{ Natural ligand } \\
\hline & R1-1-RANTES & ASTSSSGASACC & antagonist & KD et al., unpublished \\
\hline & R1-2-RANTES & LSSTSSQSPPCC & antagonist & KD et al., unpublished \\
\hline \multirow{3}{*}{ CX3CR1 } & Fractalkine/CX3CL1 & QHHGVTKC & \multicolumn{2}{|l|}{ Natural ligand } \\
\hline & F1-CX3CL1 & ILDNGVSKC & $\begin{array}{l}\text { Antagonist, } \\
\text { anti-inflammatory }\end{array}$ & $\begin{array}{l}\text { (Dorgham et al, 2009), } \\
\text { (Poupel et al, 2013) }\end{array}$ \\
\hline & F3-CX3CL1 & QPGGVSKC & Agonist & KD et al., unpublished \\
\hline
\end{tabular}

Table 3. A summary of chemokine analogs that we have isolated using the methods described in this chapter.

\section{The atypical chemokine receptor DARC (ACKR1)}

The atypical chemokine receptor DARC (Duffy antigen receptor for chemokines) (known as ACKR1) (Horuk, 2015) is a highly promiscuous receptor with a number of natural ligands, including RANTES/CCL5 and IL-8/CXCL8 (Neote, Mak, Kolakowski, and Schall, 1994). We constructed N-terminally extended libraries based on these two chemokines of the form X-X-X-X-X-RANTES/CCL5(5-68) and X-X-X-X-X-IL-8/CXCL8(10-77) (see Table 2) and 
selected them on CHO-cells stably expressing ACKR1 using the Option 1 method described in Section 2.2. Several independent selection experiments were carried out using the IL8/CXCL8 library but in each case frameshift and deletion mutants accumulated. The first selection we performed using the RANTES/CCL5 library yielded a clone capable of blocking binding of an anti-ACKR1 antibody ACKR1-expressing cells, but its activity was only marginally superior to that of native CCL5. Interestingly, this clone featured a deletion mutation eliminating Pro9. Subsequent selection experiments carried out using the same library led to accumulation of frameshift and deletion mutants, and the project was abandoned.

There are several potential explanations for our ability to isolate promising analogs acting on ACKR1. Firstly, the libraries we constructed may have been of sub-optimal quality. When we sequenced clones picked at random from the starting IL-8/CXCL8 library we noted that almost $50 \%$ of the clones encoded frameshift mutations in the $\mathrm{N}$-terminal region encoded by the degenerate oligonucleotide that was used to construct the library. The problems we encountered with this library were most likely due to the poor quality of the custom synthesized degenerate oligonucleotide primer. This was not the explanation for selection failure with the RANTES/CCL5 library, however. Sequence analysis of the starting library showed a much higher proportion of full-length, in-frame clones, and when the library was used in a selection experiment on CHO cells expressing CCR5, we readily isolated several clones with anti-HIV potencies comparable with those obtained in previous selection on CCR5 of a primary library (Hartley et al, 2003), including 9P10-RANTES (Table 3).

A second potential explanation is that our initial library design was not appropriate for selecting analogs active on ACKR1. In this regard it is interesting to note that the one potential lead we obtained in this selection experiment was a clone encoding a rare codon deletion corresponding to Pro $^{9}$ that must have been introduced during the PCR library amplification step. With this result in mind it may have been better to have started with a non extended library i.e. X-X-X-X-X-RANTES/CCL5(6-68) rather than the one-residue Nterminally extended library that we used.

We suspect that the two issues outlined above, (i) poor library quality and/or (ii) inappropriate library design, are the most likely explanations for failures with chemokine phage display that we have experienced. While we cannot eliminate the possibility that some chemokine receptors may be intrinsically less susceptible to modulation by chemokine analogs than others, or that some chemokines are intrinsically less suitable for phage display, our recommendation is that researchers should (i) be ready to restart library construction if the quality of the library appears to be compromised by mutations and deletions, and (ii) be aware that their initial library design may not be the best, and that several false starts might be required before a selection program can really gain momentum. 


\section{Perspectives}

In this section we will briefly highlight the successes that we have achieved with chemokine phage display and the perspectives for further use of the analogs that were isolated.

\subsection{A chemokine-based HIV prevention strategy}

Starting with promising ligands isolated from an initial selection (Hartley et al, 2003), we used a chemokine walking approach involving second and third-generation libraries to isolate a range of highly potent anti-HIV chemokine analogs (Gaertner et al, 2008). Two of the most promising analogs, 5P12-RANTES and 6P4-RANTES shown to be fully effective in the macaque vaginal challenge model for HIV prevention (Veazey et al, 2009), and both showed excellent stability to temperature, to vaginal $\mathrm{pH}$, in the presence of human vaginal lavage and in the presence of human semen (Cerini et al, 2008). 5P12-RANTES, which was also shown to present an exceptionally high barrier to the development of HIV escape mutants in vitro (Nedellec et al, 2011), was taken forward for further development. A scalable, low-cost cGMP-compliant production process for clinical grade 5P12-RANTES has been developed (OH et al., under revision), and work required to bring 5P12-RANTES vaginal gel into a first clinical trial is almost complete.

\subsection{New tools to study CCR5 pharmacology and cell biology}

The selection strategy used to isolate anti-HIV analogs such as 5P12-RANTES and 6P4RANTES was designed to favor analogs pharmacologically similar to the chemically synthesized prototype PSC-RANTES i.e. CCR5 superagonists capable of strongly inducing receptor sequestration. While the selection program did indeed yield analogues pharmacologically equivalent to PSC-RANTES such as 6P4-RANTES, it also provided highly potent HIV entry inhibitors with strikingly different pharmacological profiles (Gaertner et al, 2008).

One example is 5P12-RANTES, which belongs to a group of highly potent analogs that neither activate receptor signaling nor elicit receptor internalization. Another example is 5P14-RANTES, which elicits receptor internalization in the absence of $\mathrm{G}$ protein-mediated signaling. It has been suggested that 5P14-RANTES represents a strongly biased agonist of CCR5 (Zidar, 2011), and that CCR5 internalized by 5P14-RANTES follows a distinct intracellular trafficking itinerary from that of CCR5 internalized by natural ligands and superagonists such as PSC-RANTES (Bonsch et al, 2015).

Hence aside from their potential for development as anti-HIV medicines, this set of analogs represents a valuable toolbox that can be used to better understand chemokine structureactivity relationships, particularly now that crystal structures of chemokine-chemokine receptor complexes are becoming available (Qin et al, 2015, Burg et al, 2015). 


\subsection{An intrakine to protect cells from HIV infection and a vaccine adjuvant}

P2-RANTES (Hartley et al, 2003, Jin, Kagiampakis, Li, and Liwang, 2010) was incorporated into a gene therapy approach to inhibit HIV infection. It was engineered to carry a C-terminal KDEL motif that prevents export from the endoplasmic reticulum during synthesis. When introduced into a $\mathrm{T}$ cell line, the trapped intracellular chemokine, or 'intrakine', was shown to reduce surface expression of CCR5, thereby protecting the target cells from HIV infection (Petit et al, 2014). P7-RANTES, another analog directly isolated from the initial RANTES/CCL5 library (Hartley et al, 2003), was encoded as an adjuvant in a DNA vaccine strategy, and demonstrated to be capable of enhancing anti-tumor immune responses by increasing levels of local leukocyte recruitment (Dorgham et al, 2008).

\subsection{A prototypic inhibitor of CX3CR1, the Fractalkine/CX3CL1 receptor}

CX3CR1 and its only known chemokine ligand, CX3CL1, are implicated in a range of inflammatory diseases (D'Haese, Friess, and Ceyhan, 2012). We generated a Fractalkine/CX3CL1 library (Table 2) and subjected it to selection on CX3CR1-expressing cells using the Option 2 method described in Section 2.2. We isolated a variant called F1CX3CL1, which binds to CX3CR1 with an affinity comparable to that of the native ligand without inducing chemotaxis, receptor internalization or intracellular calcium response. F1CX3CL1 functions as an antagonist, inhibiting CX3CL1-induced calcium flux, chemotaxis and cell adhesion in vitro, as well as macrophage recruitment in a non-infectious murine model of peritonitis (Dorgham et al, 2009). F1-CX3CL1 is a prototypic CX3CR1 blocker that is now commonly used to demonstrate the involvement of the CX3CR1/CX3CL1 axis in in vitro disease models (e.g. (Ren et al, 2014, Gaudin et al, 2011). F1-CX3CL1 has also been shown to be active in a murine model of neovascularization (Kumar et al, 2013) and to modulate monocyte recovery after myeloablation (Jacquelin et al, 2013). Finally, F1CX3CL1 was shown to be a potent inhibitor of the progression of atherosclerotic lesions through its capacity to selectively inhibit the activity of inflammatory monocytes (Poupel et al, 2013). 


\section{References}

1. Griffith, J. W., Sokol, C. L., and Luster, A. D. (2014) Chemokines and chemokine receptors: positioning cells for host defense and immunity. Annu Rev Immunol 32, 659-702

2. Raman, D., Sobolik-Delmaire, T., and Richmond, A. (2011) Chemokines in health and disease. Exp Cell Res 317, 575-589

3. Koelink, P. J., Overbeek, S. A., Braber, S., de Kruijf, P., Folkerts, G., Smit, M. J., and Kraneveld, A. D. (2012) Targeting chemokine receptors in chronic inflammatory diseases: an extensive review. Pharmacol Ther 133, 1-18

4. Balkwill, F. R. (2012) The chemokine system and cancer. J Pathol 226, 148-157

5. Bobanga, I. D., Petrosiute, A., and Huang, A. Y. (2013) Chemokines as Cancer Vaccine Adjuvants. Vaccines (Basel) 1, 444-462

6. Kuhmann, S. E., and Hartley, O. (2008) Targeting Chemokine Receptors in HIV: A Status Report. Annu Rev Pharmacol Toxicol 48, 425-461

7. Viola, A., and Luster, A. D. (2008) Chemokines and their receptors: drug targets in immunity and inflammation. Annu Rev Pharmacol Toxicol 48, 171-197

8. Kuritzkes, D., Kar, S., and Kirkpatrick, P. (2008) Fresh from the Pipeline: Maraviroc. Nat Rev Drug Discov 7, 15-16

9. Uy, G. L., Rettig, M. P., and Cashen, A. F. (2008) Plerixafor, a CXCR4 antagonist for the mobilization of hematopoietic stem cells. Expert opinion on biological therapy 8, 1797-1804

10. Fernandez, E. J., and Lolis, E. (2002) Structure, function, and inhibition of chemokines. Annu Rev Pharmacol Toxicol 42, 469-499

11. Wells, T., Proudfoot, A., Power, C. A., Lusti-Narasimhan, M., Alouani, S., Hoogewerf, A. J., and Peitsch, M. C. (1996) The Molecular Basis of the Chemokine/Chemokine Receptor Interaction- Scope for Design of Chemokine Antagonists. Methods 10, 126-134

12. Allen, S. J., Crown, S. E., and Handel, T. M. (2007) Chemokine: receptor structure, interactions, and antagonism. Annu Rev Immunol 25, 787-820

13. Scholten, D. J., Canals, M., Maussang, D., Roumen, L., Smit, M. J., Wijtmans, M., de Graaf, C., Vischer, H. F., and Leurs, R. (2012) Pharmacological modulation of chemokine receptor function. British journal of pharmacology 165, 1617-1643

14. Hartley, O., and Offord, R. E. (2005) Engineering chemokines to develop optimized HIV inhibitors. Curr Protein Pept Sci 6, 207-219

15. Sidhu, S. S. (2001) Engineering M13 for phage display. Biomol Eng 18, 57-63

16. Hartley, O. (2002) The use of phage display in the study of receptors and their ligands. J Recept Signal Transduct Res 22, 373-392

17. Barbas, C. F. (2000) Phage display : a laboratory manual, Cold Spring Harbor Labortory Press, Cold Spring Harbor, NY

18. Kay, B. K., Winter, J., and McCafferty, J. D. (1996) Phage display of peptides and proteins : a laboratory manual, Academic Press, San Diego ; London

19. Clackson, T., and Lowman, H. B. (2004) Phage display : a practical approach, Oxford University Press, Oxford

20. Horuk, R., Reilly, D., and Yansura, D. (1997) Expression, purification, and characterization of Escherichia coli-derived recombinant human melanoma growth stimulating activity. Methods Enzymol 287, 3-12

21. Offord, R. E., Gaertner, H. F., Wells, T. N., and Proudfoot, A. E. (1997) Synthesis and evaluation of fluorescent chemokines labeled at the amino terminal. Methods Enzymol 287, 348-369

22. Dawson, P. E. (1997) Synthesis of chemokines by native chemical ligation. Methods Enzymol 287, 34-45

23. Clark-Lewis, I., Vo, L., Owen, P., and Anderson, J. (1997) Chemical synthesis, purification, and folding of C-X-C and C-C chemokines. Methods Enzymol 287, 233250 
24. Hoogenboom, H. R., Griffiths, A. D., Johnson, K. S., Chiswell, D. J., Hudson, P., and Winter, G. (1991) Multi-subunit proteins on the surface of filamentous phage: methodologies for displaying antibody (Fab) heavy and light chains. Nucleic Acids Res 19, 4133-4137.

25. Gaertner, H., Cerini, F., Escola, J. M., Kuenzi, G., Melotti, A., Offord, R., RossittoBorlat, I., Nedellec, R., Salkowitz, J., Gorochov, G., Mosier, D., and Hartley, O. (2008) Highly potent, fully recombinant anti-HIV chemokines: reengineering a lowcost microbicide. Proc Natl Acad Sci U S A 105, 17706-17711

26. Dorgham, K., Ghadiri, A., Hermand, P., Rodero, M., Poupel, L., Iga, M., Hartley, O., Gorochov, G., Combadiere, C., and Deterre, P. (2009) An engineered CX3CR1 antagonist endowed with anti-inflammatory activity. J Leukoc Biol 86, 903-911

27. Griffiths, A. D., Williams, S. C., Hartley, O., Tomlinson, I. M., Waterhouse, P., Crosby, W. L., Kontermann, R. E., Jones, P. T., Low, N. M., Allison, T. J., and et al. (1994) Isolation of high affinity human antibodies directly from large synthetic repertoires. The EMBO journal 13, 3245-3260

28. Hartley, O., Dorgham, K., Perez-Bercoff, D., Cerini, F., Heimann, A., Gaertner, H., Offord, R. E., Pancino, G., Debre, P., and Gorochov, G. (2003) Human immunodeficiency virus type 1 entry inhibitors selected on living cells from a library of phage chemokines. $J$ Virol 77, 6637-6644

29. Dorgham, K., Abadie, V., Iga, M., Hartley, O., Gorochov, G., and Combadiere, B. (2008) Engineered CCR5 superagonist chemokine as adjuvant in anti-tumor DNA vaccination. Vaccine 26, 3252-3260

30. Poupel, L., Boissonnas, A., Hermand, P., Dorgham, K., Guyon, E., Auvynet, C., Charles, F. S., Lesnik, P., Deterre, P., and Combadiere, C. (2013) Pharmacological inhibition of the chemokine receptor, CX3CR1, reduces atherosclerosis in mice. Arterioscler Thromb Vasc Biol 33, 2297-2305

31. Hanes, M. S., Salanga, C. L., Chowdry, A. B., Comerford, I., McColl, S. R., Kufareva, I., and Handel, T. M. (2015) Dual Targeting of the Chemokine Receptors CXCR4 and ACKR3 with Novel Engineered Chemokines. J Biol Chem

32. Zidar, D. A. (2011) Endogenous ligand bias by chemokines: implications at the front lines of infection and leukocyte trafficking. Endocrine, metabolic \& immune disorders drug targets 11, 120-131

33. Bonsch, C., Munteanu, M., Rossitto-Borlat, I., Furstenberg, A., and Hartley, O. (2015) Potent Anti-HIV Chemokine Analogs Direct Post-Endocytic Sorting of CCR5. PLOS ONE 10, e 0125396

34. Horuk, R. (2015) The Duffy Antigen Receptor for Chemokines DARC/ACKR1. Frontiers in immunology 6, 279

35. Neote, K., Mak, J. Y., Kolakowski, L. F., Jr., and Schall, T. J. (1994) Functional and biochemical analysis of the cloned Duffy antigen: identity with the red blood cell chemokine receptor. Blood 84, 44-52

36. Veazey, R. S., Ling, B., Green, L. C., Ribka, E. P., Lifson, J. D., Piatak, M., Jr., Lederman, M. M., Mosier, D., Offord, R., and Hartley, O. (2009) Topically applied recombinant chemokine analogues fully protect macaques from vaginal simianhuman immunodeficiency virus challenge. J Infect Dis 199, 1525-1527

37. Cerini, F., Landay, A., Gichinga, C., Lederman, M. M., Flyckt, R., Starks, D., Offord, R. E., Le Gal, F., and Hartley, O. (2008) Chemokine analogues show suitable stability for development as microbicides. J Acquir Immune Defic Syndr 49, 472-476

38. Nedellec, R., Coetzer, M., Lederman, M. M., Offord, R. E., Hartley, O., and Mosier, D. E. (2011) Resistance to the CCR5 Inhibitor 5P12-RANTES Requires a Difficult Evolution from CCR5 to CXCR4 Coreceptor Use. PLoS ONE 6, e22020

39. Qin, L., Kufareva, I., Holden, L. G., Wang, C., Zheng, Y., Zhao, C., Fenalti, G., Wu, H., Han, G. W., Cherezov, V., Abagyan, R., Stevens, R. C., and Handel, T. M. (2015) Structural biology. Crystal structure of the chemokine receptor CXCR4 in complex with a viral chemokine. Science 347, 1117-1122 
40. Burg, J. S., Ingram, J. R., Venkatakrishnan, A. J., Jude, K. M., Dukkipati, A., Feinberg, E. N., Angelini, A., Waghray, D., Dror, R. O., Ploegh, H. L., and Garcia, K. C. (2015) Structural biology. Structural basis for chemokine recognition and activation of a viral G protein-coupled receptor. Science 347, 1113-1117

41. Jin, H., Kagiampakis, I., Li, P., and Liwang, P. J. (2010) Structural and functional studies of the potent anti-HIV chemokine variant P2-RANTES. Proteins 78, 295-308

42. Petit, N., Dorgham, K., Levacher, B., Burlion, A., Gorochov, G., and Marodon, G. (2014) Targeting both viral and host determinants of human immunodeficiency virus entry, using a new lentiviral vector coexpressing the T20 fusion inhibitor and a selective CCL5 intrakine. Hum Gene Ther Methods 25, 232-240

43. D'Haese, J. G., Friess, H., and Ceyhan, G. O. (2012) Therapeutic potential of the chemokine-receptor duo fractalkine/CX3CR1: an update. Expert Opin Ther Targets $16,613-618$

44. Ren, J., Hou, X. Y., Ma, S. H., Zhang, F. K., Zhen, J. H., Sun, L., Sun, Y. X., Hao, Y. L., Cheng, Y. F., Hou, M., Xu, C. G., Zhang, M. H., and Peng, J. (2014) Elevated expression of $\mathrm{CX} 3 \mathrm{C}$ chemokine receptor 1 mediates recruitment of $\mathrm{T}$ cells into bone marrow of patients with acquired aplastic anaemia. J Intern Med 276, 512-524

45. Gaudin, F., Nasreddine, S., Donnadieu, A. C., Emilie, D., Combadiere, C., Prevot, S., Machelon, V., and Balabanian, K. (2011) Identification of the chemokine CX3CL1 as a new regulator of malignant cell proliferation in epithelial ovarian cancer. PLoS ONE 6, e21546

46. Kumar, A. H., Martin, K., Turner, E. C., Buneker, C. K., Dorgham, K., Deterre, P., and Caplice, N. M. (2013) Role of CX3CR1 receptor in monocyte/macrophage driven neovascularization. PLOS ONE 8, e57230

47. Jacquelin, S., Licata, F., Dorgham, K., Hermand, P., Poupel, L., Guyon, E., Deterre, P., Hume, D. A., Combadiere, C., and Boissonnas, A. (2013) CX3CR1 reduces Ly6Chigh-monocyte motility within and release from the bone marrow after chemotherapy in mice. Blood 122, 674-683 